\title{
The World's First Human Case of H10N8 Influenza
}

\section{Yingying Ding ${ }^{1 *}$ and Shunquan $\mathbf{W u}^{2}$}

${ }^{1}$ Department of Medical Microbiology, Second Military Medical University, Shanghai-200433, China

${ }^{2}$ Department of Health Statistics, Second Military Medical University, Shanghai-200433, China

A human infection case of H10N8 influenza virus, a new strain of avian influenza virus, was confirmed on December 18, 2013 in Nanchang, Jiangxi Province of China.

The patient was a 73-year-old woman, who was diagnosed as severe pneumonia, accompanied by high blood pressure, heart disease, myasthenia gravis and other underlying diseases, with a low immunity level. She had been under treatment since November 30 in a hospital in the provincial capital of Nanchang and died on December 6 due to respiratory failure and shock. Influenza A virus was detected in the sample of this case and was further identified as H10N8 avian influenza virus by the Chinese Center for Disease Control and Prevention. The patient had exposure history of live poultry business market. All close contacts have not appeared abnormal symptoms so far [1].

The influenza A virus family is distinguished by two proteins protruding from the virus surface, namely the hemagglutinin and neuraminidase (short for " $\mathrm{H}$ " and "N"). There are a total of $16 \mathrm{H}$ and $9 \mathrm{~N}$ in this big "family", and different viruses are named with their different combinations of $\mathrm{HxNy}$, such as H1N1, H2N2, H7N9 etc. Among all $16 \mathrm{H}$ and $9 \mathrm{~N}$ subtypes of influenza A viruses, the highly pathogenic avian influenza viruses are restricted to subtypes $\mathrm{H} 5, \mathrm{H} 7$ and $\mathrm{H}$, although not all $\mathrm{H} 5, \mathrm{H} 7$ and $\mathrm{H} 9$ viruses are virulent. Other subtypes of avian influenza viruses (other than $\mathrm{H} 5, \mathrm{H} 7$ and $\mathrm{H} 9$ ) might evolve to pose a potential threat to mammals and even humans. Therefore, when emphasis is placed on $\mathrm{H} 5, \mathrm{H} 7$ and $\mathrm{H} 9$ subtype avian influenza viruses, the other subtypes should not be ignored, because they might also be a potential threat to public health.

The H10N8 avian flu virus has already existed in nature before. It has been isolated from quails in as early as 1965 [2,3]. Since then, it was also been found in Australia, Sweden, North America and Asia [3,4]. In China, an H10N8 avian influenza virus was ever isolated from Dongting Lake wetland, Yueyang City, Hunan Province in 2007 and phylogenetic analysis indicated that the virus was generated by multiple gene segment reassortment [5]. It was also isolated from a duck in a live bird market in Guangdong Province of southern China in January, 2012 [6]. However, this patient is the world's first confirmed human infection case of H10N8 influenza that had never been reported before. Some experts believe that this is only an individual case and there is a low risk for the virus to cause infection and transmission among human.

Yet for now, this virus may have the ability to infect people, in addition, it is not easy to judge whether the infection ability of H10N8 will be strengthened or weakened in the future. According to genetic analysis, this virus is attenuated virus in poultry. In order to prevent the further expansion of the scope of infection, it is necessary for us to pay close attention to it. Virological and serological surveillance should be enhanced in live poultry markets and wild bird habitats to make detection on the prevalence of the virus among the avian species and genetic markers for mammalian adaptations.

\section{References}

1. http://www.chinadaily.com.cn/china/2013-12/18/content_17182103.htm.

2. De Marco MA, Campitelli L, Foni E, Raffini E, Barigazzi G, et al. (2004) Influenza surveillance in birds in Italian wetlands (1992-1998): is there a host restricted circulation of influenza viruses in sympatric ducks and coots? Vet microbiol 98: 197-208.

3. http://www.ncbi.nlm.nih.gov/genomes/FLU/Database/nph-select. cgi?go=database.

4. Manzoor R, Sakoda Y, Mweene A, Tsuda Y, Kishida N, et al. (2008) Phylogenic analysis of the $\mathrm{M}$ genes of influenza viruses isolated from free-flying water birds from their Northern Territory to Hokkaido, Japan. Virus Genes 37: 144-152.

5. Zhang H, Xu B, Chen Q, Chen J, Chen Z (2011) Characterization of an H10N8 influenza virus isolated from Dongting lake wetland. Virol J 8: 42.

6. Jiao P, Cao L, Yuan R, Wei L, Song Y, et al. (2012) Complete genome sequence of an H10N8 avian influenza virus isolated from a live bird market in Southern China. J Virol 86: 7716.
*Corresponding author: Yingying Ding, Department of Medical Microbiology, Second Military Medical University, Shanghai-200433, China, Tel: 8621 81870989; E-mail: aydingyingying@163.com

Received June 26, 2015; Accepted February 29, 2016; Published March 03 2016

Citation: Ding Y, Wu S (2016) The World's First Human Case of H10N8 Influenza J Pulm Respir Med 6: 323. doi:10.4172/2161-105X.1000323

Copyright: (c) 2016 Ding Y, et al. This is an open-access article distributed under the terms of the Creative Commons Attribution License, which permits unrestricted use, distribution, and reproduction in any medium, provided the original author and source are credited. 